\title{
EL ESQUEMATISMO TRASCENDENTAL KANTIANO A LA LUZ DE LA DOCTRINA DEL LÍMITE MENTAL
}

\author{
THE KANTIAN TRANSCENDENTAL SCHEMATISM TO THE LIGHT OF \\ THE DOCTRINE OF MENTAL LIMIT
}

\author{
Fernando Haya ${ }^{1}$ \\ I.E.S. Hermanos Machado, Sevilla (España)
}

Recibido: 20-05-2014

Aceptado: 10-08-2014

\begin{abstract}
Resumen: Se confrontan los paradigmas intelectivos correspondientes a Kant y a Polo, que en función del tiempo se designan respectivamente como esquema trascendental y articulación presencial del tiempo. La discrepancia con Kant surge a partir de la descripción poliana del comienzo intelectual como adelantamiento del saber con relación al tiempo. En Kant la intelección salta también sobre el tiempo, pero con un salto bien corto, en dependencia de su idea de la intelección como función categorial en relación con la pluralidad temporal. En consecuencia, el principio trascendental kantiano carece de la amplitud suficiente para incoar el método.

Palabras-clave: Kant, Polo, tiempo, esquematismo trascendental, articulación presencial del tiempo.
\end{abstract}

\begin{abstract}
Are here confronted intellection paradigms corresponding to Kant and Polo, which, depending on the time, are respectively designated as transcendental scheme and articulation of time in the presence. The discrepancy with Kant emerges in the polian description of the intellectual start as advancement of knowledge in relation to time. Kant intellection rises over time, but with a very short hop, depending on his idea of understanding how categorial function dealing with the temporal plurality. Consequently, the transcendental principle in Kant is not of sufficient amplitude to initiate the method.

Key-words: Kant, Polo, time, transcendental schematism, articulation of time in the presence.
\end{abstract}

[1] (fhayasegovia@gmail.com) Es autor de los libros Tomás de Aquino ante la crítica, EUNSA, Pamplona, 1992; El ser personal, EUNSA, Pamplona, 1997; La fenomenología metafísica de Edith Stein, Cuadernos de Anuario Filosófico, Servicio de Publicaciones de la Universidad de Navarra, 1997; Tiempo y método en Max Scheler, Cuadernos de Anuario Filosófico, Servicio de Publicaciones de la Universidad de Navarra, 2011; así como de numerosos artículos en revistas especializadas de Filosofía. Es Profesor de Enseñanza Secundaria en el IES Hermanos Machado de Sevilla. 


\section{Planteamiento: la contraposición del paradigma intelectivo en función del tiempo ${ }^{2}$}

La expresión paradigma intelectivo quiere aludir al modelo teórico -nocional- que vierte la exposición de la actividad intelectual. Paradigma de la intelección en función del tiempo significa, pues, modelo gnoseológico inclusivo de la referencia expresa al tiempo. Contrapondremos aquí los paradigmas de la intelección correspondientes a Kant y Polo, que, en función del tiempo, son respectivamente designados como esquema trascendental y articulación presencial del tiempo ${ }^{3}$.

Advirtamos que por ahora sólo en sentido nominal queda el entender caracterizado en función del tiempo. La inclusión de la referencia al tiempo en el paradigma intelectivo no basta para determinar el sentido direccional de la función. La contraposición de paradigmas intelectivos se dirige precisamente a averiguar si efectivamente la intelección es -como quiere el primer Heidegger-función de la temporalidad; o si, por el contrario -como sugiere Aristóteles y más claramente San Agustín-, es el tiempo el que debe ponerse en función del entender.

La posición de Polo cae del lado aristotélico, mientras que Heidegger ${ }^{4}$ conduce el tratamiento de Kant al establecimiento del estatuto de la intelección en función del tiempo. El propio Aristóteles ${ }^{5}$ vacila en decidir si la medida del movimiento depende del movimiento del cielo o es más bien introducida por el

[2] Agradezco al Profesor Jacinto Choza su invitación a participar con este trabajo en el homenaje de Thémata a nuestro común maestro y amigo Leonardo Polo, recientemente fallecido.

[3] Estas páginas se insertan dentro del contexto de una investigación más amplia, que percibe en el método poliano del abandono del límite mental una rectificación del método trascendental de Kant. Una rectificación que a mi modo de ver difiere toto coelo de la propuesta por el llamado tomismo trascendental. Como es bien sabido, esta última corriente de pensamiento fue instaurada por J. Maréchal en su magna obra Le point de départ de la Métaphysique; vid. especialmente Cahier V, Le Thomisme devant la Philosophie critique, 10ª ed., Desclée de Brouwer, Paris, 1949 (Trad. cast. de F. Font y S. Heredia, El punto de partida de la Metafísica, Editorial Gredos, Madrid, 1959). Discutí ampliamente, desde la perspectiva de Polo, la posición del tomismo trascendental en Tomás de Aquino ante la crítica. La articulación trascendental de conocimiento y ser, EUNSA, Pamplona, 1992, pp. 151-179. El sentido de la rectificación trascendental de la filosofía crítica tal como yo la entiendo resultaría en cambio próxima a la crítica de Max Scheler a Kant, especialmente en Der Formalismus in der Ethik und die materiale Werthetik, GW,2 ( trad. de H. Rodríguez, Ética, Caparrós, Madrid, 2001), y en Die Idole der Selbsterkenntnis, GW, 3 (trad. I. Vendrell, Los idolos del autoconocimiento, Sígueme, Salamanca, 2003), tal como he expuesto en Tiempo y método en Max Scheler, Cuadernos de Anuario Filosófico, no 234, Servicio de Publicaciones de la Universidad de Navarra, Pamplona, 2011, pp. 55-81. Para un estudio paralelo al desarrollado en las presentes páginas, aunque centrado en el problema del juicio, cfr. mi trabajo El estatuto del juicio como función de atenencia, en Haya, F. (ed. asoc.), Polo ante la Crítica, Studia Poliana, XVI ( 2014), pp. 61-82.

[4] Vid. Heidegger, M., Kant und das Problem der Metaphysic, V. Klostermann, Frankfurt, Main, 1973; trad. cast. G.I. Roth-E.C. Frost, Kant y el problema de la metafísica, FCE, Madrid, 1993.

[5] Cfr. Aristóteles, Physic. IV, 223 a 16 y ss.

THÉMATA. Revista de Filosofía, №50 julio-diciembre (2014) pp.: 151-175 doi: 10.12795/themata.2014.i50.07 
alma, la instancia medidora. Al cabo, Aristóteles parece asumir ambas posiciones, cuya compatibilidad resulta propiciada por la doble consideración -en potencia y en acto- de lo numerable: así, el tiempo sería real como lo es el movimiento, en el sentido en que lo es lo numerable en potencia; considerado en cambio como lo numerable en acto, el tiempo quedaría en función del entender. La intelección -el acto de entender-introduce la medida en acto, según la que se discierne -y se mide- el tránsito del antes al después.

La expresión poliana "articulación del tiempo en presencia" resulta próxima a Aristóteles. Dice Polo: "Como comienzo, la presencia articula el tiempo sin formar parte de él. Articular el tiempo no es sumirse en el orden de la realidad externa, sino pensar. La distribución real es antes y después; articularlos es objetivar"6. La posición de Polo se comprende bien desde la atención que el autor dispensa a la noción aristotélica de práxis, actividad posesiva de fin. Se entiende y se ha entendido, simul; sin que medie tiempo, el objeto es inmanentemente poseído por la operación. En cambio, el movimiento (kínesis) se distiende - en el tiempo- hacia un fin extrínseco, no poseído en perfecto.

Pero si tal es la condición, el estatuto del objeto poseído por la operación mental -a saber, la presencia-, entonces la presencia mental no pertenece al tiempo, sino que se introduce en él en el modo de articularlo entero. Se comprende que la presencia mental no pertenezca al tiempo puesto que en la naturaleza temporal de las cosas no hay tal posesión inmediata del fin. La presencia mental no pertenece sin más al orden de lo físico. Es introducida por el alma.

De otra parte, el tiempo es articulado desde el presente. El presente articula el tiempo porque el pasado se entiende como lo que fue presente y el futuro como lo que será presente. Dice Polo: "Abstraer es la consideración presencial del tiempo. El tiempo es antes, ahora y después. Entiendo por determinación directa (...) el tiempo articulado. El tiempo no está articulado si no es pasado, presente y futuro, o bien, antes, ahora y después". Y añade: "Si tenemos los tres términos, cabe proceder prescindiendo de alguno: por ejemplo, se puede prescindir del presente y dejar el futuro y el pasado (el después y el antes), sin presente. No excluyo -sino todo lo contrario- que tal sentido del tiempo sea válido -real-" obstante, "cualquiera que sea el modo de entender la temporalidad en términos de antes y después, sin presente no es ningún objeto".

De esta forma el tiempo conforma la serie de los presentes, una serie continua, como si el ahora del presente se extendiera sin fragmentación en un sentido y en otro: una extensión articulada, pues, no fragmentada o dispersa. De tal modo además que esta serie entera del tiempo -indefinida hacia atrás

[6] Polo, L., Curso de teoría del conocimiento t. III, EUNSA, Pamplona, 1988, p. 325.

[7] Id., p. 325.

[8] Ibid.

[9] Ibid.

THÉMATA. Revista de Filosofía, №50 julio-diciembre (2014) pp.: 151-175 doi: 10.12795/themata.2014.i50.07 
y hacia delante- parece aportar el marco más extenso para la ocurrencia de la realidad física. En efecto, incluso lo contradictorio en el instante -predicados de un mismo sujeto opuestos por la negación-deja de serlo cuando se alberga en la más extensa serie del tiempo. Que la abstracción es el comienzo intelectual significa, según Polo, introducción del articularse del tiempo y por ello mismo obtención de la determinación directa: "Entiendo por determinación directa (...) el tiempo articulado"10.

Antes de pasar a Kant, intentaré precisar brevemente la noción de Polo. En continuidad con la tradición aristotélica -aunque modificando la terminología- Polo llama abstracto al objeto de la primera operación intelectual. Polo conviene con Tomás de Aquino en que el objeto de la inteligencia humana es la quidditas rei sensibilis. Con vistas a la claridad expositiva podemos aplicar al abstracto la inevitable -por indispensable- distinción escolar que discierne los aspectos material y formal de la cosa considerada. Quedaría entonces que: 1) El contenido - materia- del abstracto es la determinación inteligible directa, la quidditas rei sensibilis, que en sentido amplio puede llamarse también esencia $^{11}$. 2) La forma del abstracto, esto es, su estatuto objetivo, sería la presencia, en virtud de la cual la determinación inteligible es exhibida en directo. Resultaría indispensable en cambio evitar la consideración hilemórfica en el sentido de amalgamar la forma del conocimiento con su contenido intencional, al modo como precisamente hace Kant. Está claro que en tal caso el contenido intencional se pierde y no cabe hablar de determinación inteligible directa.

Adviértase a continuación lo siguiente: según Polo, la esencia inteligible no sólo es obtenida en presencia, o según la forma del entender que articula el tiempo, sino que el contenido directamente conocido es temporal: si el tiempo no quedara también concernido en la noticia directamente entendida -en el contenido intencional abstracto-, ¿cómo podría decirse que el objeto propio de la inteligencia humana es la quidditas rei sensibilis? En tal sentido afirma Polo que el abstracto -la determinación directa- es el tiempo articulado.

Este es el punto que, a mi modo de ver, ofrece mayor dificultad en la interpretación de la noción poliana de articulación presencial del tiempo. La presencia mental es articulación del tiempo entero -dice Polo- y en función de ello exhibe determinación directa; pero, de otra parte: a la misma determinación directa puede llamarse articulación del tiempo entero. Parecería seguirse pues que lo exhibido en directo es la articulación del tiempo entero, y, sin embargo, no puede ser así porque entonces lo presente sería el límite mental mismo,

[10] Id., p. 325 .

[11] En sentido amplio, porque en sentido propio, la denominación de esencia queda reservada en la terminología poliana al explícito de la operación judicativa, esto es, al orden de la cuádruple concausalidad, la esencia única del universo. Cfr. Polo, L., Curso de teoría del conocimiento t. IV, EUNSA, Pamplona, 2004, pp. 558 y ss.

THÉMATA. Revista de Filosofía, №50 julio-diciembre (2014) pp.: 151-175 doi: 10.12795/themata.2014.i50.07 
que es justo lo prohibido en la propuesta de su abandono ${ }^{12}$. Me parece que el problema se resuelve si se repara en el núcleo del descubrimiento: la presencia mental como articulación del tiempo entero significa la transparencia con que la forma del tiempo es recorrida por la intelección de modo que deja de oponer obstáculo - deja de interponerse- a la directa exhibición de lo inteligible.

Lo inteligible -simplemente lo-, la quidditas rei sensibilis, está presente al entender en virtud de que el tiempo ya no se interpone porque su forma se vuelve transparencia. La intelección articula el tiempo reduciendo su forma a la transparencia que exhibe en directo: lo exhibido es la determinación real inteligible. La pregunta es pues ésta: ¿Lo exhibido mismo es tiempo? Y la respuesta sólo puede ser: lo exhibido en presencia es lo temporal del tiempo vencida la opacidad de la forma temporal que se interpone; o más propiamente, convertida en trasparencia aquella opacidad. Examinemos a continuación el modelo de Kant.

\section{El esquematismo trascendental como paradigma de la intelección}

A Kant debe atribuirse la inspiración original del método trascendental, que -en sentido rectificado- sigue Polo: establecimiento de la correlación entre los objetos del pensamiento y sus actos correspondientes. Al propio Kant se deben tanto la denominación como el relieve que hayan sin duda de otorgarse al concepto y a la condición de lo a priori, cuyo significado etimológico alude precisamente al tiempo. Y asimismo en el mismo Kant encontramos los desarrollos que sugieren la índole articulativa del tiempo a que venimos haciendo referencia, puesto que por esquemas trascendentales no entiende el autor sino configuraciones temporales. Es una lástima, a mi juicio, que tan buenos mimbres forjen al cabo un sistema filosófico tan estrecho.

La noción de configuración temporal está presente en la Analítica trascendental, vertida en un concepto -el de esquema trascendental- sumamente sugerente. Si se prescinde de la insistente tematización constructiva del conocimiento, la noción de esquema trascendental ilustra bien qué pueda entenderse por articulación del tiempo, y manifiesta -contra el propio autor- que la articulación temporal excede la representación del tiempo como secuencia. La noción kantiana de fenómeno como configuración temporal vinculada con la unidad abarcante del tiempo es aprovechable. La intuición de Kant -luego compartida por Husserl- hace de la unidad del tiempo garantía de la objetividad de los fenómenos, es decir, de su incardinación en la realidad empírica.

Tal es el sustento teórico de los desarrollos contenidos en la Analítica trascendental, en especial el de su Segundo y difícil Libro, donde se trata de la

[12] "El tiempo como articulación no es una representación destacada enfrente; pertenece a la presencia y ha de referirse a la presencia carente de automanifestación”. Polo, L., El acceso al ser, EUNSA, Pamplona, 2004, $2^{\text {a }}$ ed., p. 48.

THÉMATA. Revista de Filosofía, №50 julio-diciembre (2014) pp.: 151-175 doi: 10.12795/themata.2014.i50.07 
Analitica de los principios. La deducción trascendental de los conceptos puros se vierte a esta sección de la Crítica en la exposición que insiste en hacer de la unidad inteligible del tiempo condición a priori del objeto de experiencia: "Es, pues, la posibilidad de la experiencia lo que da realidad objetiva a todos nuestros conocimientos a priori. Ahora bien, la experiencia se basa en la unidad sintética de los fenómenos, es decir, en una síntesis conceptual del objeto de los fenómenos en general. Sin esa síntesis, la experiencia no sería siquiera conocimiento. Sería una rapsodia de percepciones que no adquirirían cohesión en ningún contexto regulado por normas (...)"13.

El camino de la deducción trascendental es de ida y vuelta. La legalidad, el derecho en el uso de las categorías -los conceptos a priori- se sustenta en la posibilidad de la experiencia. Las categorías son objetivas porque definen el marco de la experiencia posible. Pero, en sentido inverso, la propia experiencia (real y posible) "se basa en la unidad sintética de los fenómenos, es decir, en una síntesis conceptual del objeto de los fenómenos en general"14. ¿Qué lugar ocupa aquí el tiempo? Ha respondido el propio Kant, unas líneas más arriba: "Una vez concedido que hay que ir más allá de un concepto dado para confrontarlo sintéticamente con otro, hace falta un tercer elemento que es el que permite la síntesis de los dos conceptos"15. Y añade: “En qué consiste este tercer elemento en cuanto medio de todos los juicios sintéticos? No hay más que un todo en el que se hallen contenidas todas nuestras representaciones, a saber, el sentido interno, y la forma a priori del mismo, el tiempo"16.

El problema que a mi modo de ver presenta la especulación kantiana sobre el tiempo es su indudable miopía para calibrar la instancia que habría de ofrecer el principio mismo de la articulación temporal plena. Este elemento es ciertamente la presencia mental, descrita en el paradigma de Polo. Pero la presencia mental resbala, queda ignorada una y otra vez entre los párrafos de Kant.

Desglosaremos a continuación las tres averiguaciones kantianas aludidas, exponiéndolas junto con su rectificación desde la perspectiva de Polo. Se ha dicho que Kant descubrió el carácter de lo a priori como punto de partida o comienzo de la metodología trascendental; que Kant destacó más que ningún otro que el tiempo es forma de lo sensible conocido, y, además de forma, configurable, puesto que cabe hablar de esquemas o reglas de configuración del tiempo; en tercer lugar, se ha dicho que Kant insistió antes que Husserl en que la unidad del tiempo es la garantía de la objetividad de los fenómenos.

[13] Kant, I., Kritik der reinen Vernunft (KrV), Hartknoch, Riga, 1781 (A); 1787 (B), 156 B 196. Sigo la traducción de Pedro Ribas en la edición de Alfagüara-Santillana, Madrid, 1994.

[14] Ibid.

[15] $K r V$ B 194 A 155.

[16] Ibid.

THÉMATA. Revista de Filosofía, N50 julio-diciembre (2014) pp.: 151-175 doi: 10.12795/themata.2014.i50.07 


\section{a) El a priori como comienzo trascendental}

El paradigma de la intelección, como hemos llamado antes a su noción explicativa, corresponde a una exposición gnoseológica y concierne por tanto a la doctrina del método de la filosofía. Si la cuestión suscitada se refiere, como en nuestro caso, a la relación que se establece entre el pensar y el tiempo, parece razonable plantear el problema del comienzo del pensar. Así lo hace Polo en las páginas del Curso ya citadas, especialmente en discusión con Hegel.

Frente al comienzo absoluto hegeliano, Polo establece el comienzo filosófico en conexión con la dinámica natural del conocimiento humano. Podríamos decir que según Polo la filosofía comienza en el comienzo ${ }^{17}$. Este filosofema vertería bien a mi juicio el espíritu de la gnoseología de Polo. No obstante, convendrá depurar el significado del término comienzo referido al pensar, como de hecho propone Polo en estas lecciones del Curso. El significado de comienzo connota de modo inmediato el tiempo, pues propiamente se llama comienzo al inicio de una serie temporal. De modo que conviene depurar el sentido del término para que albergue la suficiente amplitud que permita referirlo al pensamiento.

Ahora bien. Cabe detectar cierto paralelismo en el planteamiento kantiano de la cuestión. Porque en efecto, Kant alude también a un significado eminente del comienzo intelectual, como distinto del inicio temporal, justo en los primeros párrafos de la Introducción a la $K r V$. Kant comienza por destacar la noción de a priori puesto que en ella se sustenta toda la idea del método trascendental: "Aunque todo nuestro conocimiento empiece con la experiencia, no por eso procede todo él de la experiencia"18. Como si dijera que la precedencia de los actos de la sensibilidad según el tiempo, no agota la significación del comienzo intelectual, puesto que la intelección no se explicaría sin dar cuenta de su rebasar la experiencia. Según la posibilidad, explorada por la filosofía trascendental del conocimiento a priori, resulta obvio que la experiencia no agota el significado intelectual del comenzar. El no derivarse de la experiencia significará para el conocimiento a priori al menos la conjugación de un sentido del comenzar cuya referencia al tiempo ha de ser diversa de la considerada en el sentido temporal de comienzo.

Comienzo puede significar inicio en la serie del tiempo, y en tal sentido afirma Kant que la intelección parte de la experiencia sensible: todo conocimiento comienza con la experiencia. De este modo el inicio intelectual queda situado en cierta serie temporal sucesiva, precedido por las operaciones

[17] Con la expresión "en el comienzo" quiero significar el inicio de la vida intelectual. Sobre tal inicio echa cuentas el método. Comenzar (metódicamente) en el comienzo equivale a retracción del método filosófico sobre el comienzo intelectual, que es la abstracción. El ajuste en cuestión es tanto aquilatamiento del valor de la abstracción como medida de su insuficiencia. Según Polo, ese ajuste abre dos líneas operacionales prosecutivas distintas: la generalización y la razón.

[18] $K r V$ B 1.

THÉMATA. Revista de Filosofía, $\mathrm{N}^{\circ} 50$ julio-diciembre (2014) pp.: 151-175 doi: 10.12795/themata.2014.i50.07 
cognoscitivas sensibles. No hay inconveniente en expresar así -con referencia a la serie temporal- la necesidad que la intelección tiene de contar con un antecedente sensible: puesto que el entendimiento carece de ideas innatas, su noticia queda precedida -en el tiempo- por determinados movimientos de la sensibilidad que a su vez responden a estimulaciones de carácter físico. No obstante, debe evitarse que la atención encalle en este marco representativo, porque en tal caso la especificidad del comienzo intelectual con referencia al tiempo pasa completamente inadvertida; es decir: no se depura el otro sentido del comienzo, el que propiamente concierne a la intelección.

En este preciso sentido afirma Polo: "Si los actos relativamente a los cuales la determinación directa es un comienzo son prosecutivos, parece que la determinación es un comienzo temporal (...). Y, efectivamente, lo sería si ella misma no fuera pensada; en cuanto que se corresponde con un acto, no está simplemente destinada a los otros. La determinación directa sería un comienzo temporal, y los actos de los cuales es comienzo serían procesos temporales, si no se correspondiera con un acto. Todo esto es solidario, y lleva consigo que la determinación directa no es el simple empezar (con lo que empezar tiene de connotación temporal) de los otros actos. Un acto no es el comienzo de otros; tampoco lo es la sola inteligencia sino la inteligencia con hábito"19.

El concepto de a priori -que guía la metodología trascendental- queda de este modo depurado. Propiamente hablando el a priori intelectual corresponde al acto, y a través del acto a las condiciones sensibles de la intelección, pero una y otra prioridad no se ponen en el mismo plano. De manera que resulta improcedente asimilar simplemente el comienzo intelectual al comienzo en el sentido de inicio temporal. Pero eso significa también que la posición kantiana sobre el a priori requiere rectificación. Kant entiende que el método de la filosofía comienza en un sentido que aventaja al tiempo, pero sólo dentro de los límites en que el entendimiento puro esboza los confines de la experiencia posible. En tal sentido, la intelección en Kant salta sobre el tiempo, pero con un salto bien corto, en dependencia de su idea del entender como función categorial referida a la pluralidad de tiempo.

En Polo, el salto intelectual sobre el tiempo es de mucha mayor envergadura, hasta el punto de que el estatuto mismo de la intelección puede describirse en los términos de adelantamiento. La intelección salta sobre el tiempo en cuanto la presencia mental se adelanta al tiempo. El objeto intelectual es presente, se muestra en presencia, en virtud del adelantamiento de la operación mental. El adelantamiento de la presencia mental es la misma articulación del tiempo, el paradigma intelectual en Polo. El adelantamiento de la presencia mental instaura el comienzo intelectual, el abstracto.

[19] Polo, L., Curso de teoría del conocimiento t. III, ed. cit., p. 322. 
Planteada en forma la sentencia kantiana antes citada no merecería reproche: todo conocimiento comienza con la experiencia, pero no todo conocimiento tiene su condición en la experiencia, puesto que al menos el acto de entender es a priori con relación a la experiencia -al tiempo-. La presencia mental se adelanta al tiempo, hasta el punto de introducirse articulándolo. La discrepancia con Kant emerge en la descripción del comienzo intelectual aquí propuesta: adelantamiento. En efecto, este último término connota el tiempo a través de cierto respecto que la crítica kantiana no contempla. Por decirlo de este modo: en el planteamiento crítico kantiano la presencia mental se retrasa: ha de forjarse proyectivamente, salir en busca de una intuición con miras a consolidar su objeto ${ }^{20}$.

En consecuencia, el principio trascendental no reviste en Kant la suficiente amplitud para incoar el método en condiciones. Descansa en definitiva en una versión pobre, disminuida, del acto intelectual. Kant compartiría hasta cierto punto que la intelección abarca el tiempo, en el sentido de que la conciencia trascendental recorre la pluralidad temporal imponiéndole la forma de su unidad posible. Pero este abarcar intelectual del tiempo resulta en Kant extrínseco: la pluralidad pura del tiempo no queda, por así decir, penetrada, puesto que el tiempo es concebido por Kant como el elemento ajeno, lo refractario mismo a la intelección. Por lo tanto, la opacidad del tiempo -a la que anteriormente nos referíamos- no llega a ser vencida: entender no es presencia, transparencia. El paradigma kantiano expone la intelección como si fuera cierta imposición extrínseca en orden a configurar, a manejar un elemento extraño, refractario; para colmo, un elemento extraño instalado en la propia estructura del sujeto a título de forma receptiva a priori.

De entrada, esta misma forma a priori resulta intencionalmente extraña a su contenido por la misma razón por la que -en el plano empírico- se amalgama con ese mismo contenido ${ }^{21}$. Conocido el fenómeno espacio-temporal, lo conocido no es su contenido de realidad, sino en todo caso la misma amalgama espacio-temporal. La forma espacio-temporal comienza por imponerse a la diferencia real estableciendo su exclusión recíproca, pero de tal suerte que lo real de la diferencia -la diferencia misma- queda en tal exclusión absolutamente ignorado.

En suma: las diferencias reales percibidas -en el espacio y en el tiempono pasan de configuración fenoménica de la propia temporalidad, y por eso esta última es como una pantalla opaca que impide simplemente el acceso intencional a lo real. Sólo queda la fijación de la objetividad fenoménica: tal es la obra del entendimiento a través de la confección de esquemas imaginativos trazados $a$ priori en la forma del tiempo. Los esquemas serían configuraciones temporales definidas, sobre la base de una pluralidad pura difusa, previamente asentada como forma del sentido interno.

[20] Cfr. Maréchal, J., o. c., trad. cit., pp. 469-470.

[21] Cfr. Scheler, M., Ética, ed. cit., pp. 124-125.

THÉMATA. Revista de Filosofía, Nº50 julio-diciembre (2014) pp.: 151-175 doi: 10.12795/themata.2014.i50.07 


\section{b) El tiempo como forma articulante y articulable}

Articulación temporal equivale, a mi modo de ver, a forma del tiempo. El tiempo es forma, orden inclusivo de ciertas determinaciones reales que serían su contenido. Pero, además, el tiempo es susceptible de adoptar diversidad de configuraciones; el tiempo es, en este último sentido, formalizable: es decir, capaz de manifestar su unidad según modalidades articulativas diversas.

El tiempo es el orden que rige la exclusión recíproca de las determinaciones o diferencias reales que sólo existen y son conocidas de este preciso modo: en recíproca exclusión ${ }^{22}$. Deben añadirse algunas precisiones: en primer lugar, el tiempo como orden de exclusión mienta en efecto cierta exterioridad recíproca de las determinaciones reales. Pero la exterioridad a que se alude no significa en exclusiva la condición del espacio. La exterioridad temporal es, por así decir, más profunda, y raíz de la exterioridad que asignamos a la extensión espacial ${ }^{23}$.

En segundo lugar, este orden de exclusión designa la unidad misma del orden excluyente. Quiero decir: el tiempo, como orden que rige la exclusión de las diferencias recíprocamente excluidas, es también la unidad de tales diferencias. A este propósito, se emplea la palabra orden según una doble significación, una más propia que otra. En sentido laxo, orden equivale a ámbito: en este sentido la unidad del tiempo puede considerarse a modo de esfera abarcante de las determinaciones o diferencias reales recíprocamente excluidas. Es decir: las diferencias se excluyen unas de otras pero todas ellas se contienen -existen- en el tiempo. Nos referimos entonces al tiempo como el orden o ámbito de los seres temporales, aquellos que existen en el tiempo.

Ahora bien. Conviene evitar la suposición del tiempo, es decir, la consideración del tiempo como sustancia que soporta o de que se nutre la realidad de los seres temporales. Pero será difícil evitar esta suposición del tiempo si nos atenemos en exclusiva a la acepción del orden temporal recién descrita. Por eso es ésta una acepción impropia, porque sugiere que el tiempo es el ser mismo de las realidades temporales, es decir, introduce con facilidad la suposición del tiempo.

Examinaremos a continuación en qué sentido cabe afirmar que el tratamiento kantiano de la temporalidad incurre en la suposición del tiempo. Kant rechaza, desde luego, la realidad metafísica del tiempo: el tiempo es forma $a$ priori de la sensibilidad. Y, no obstante, con vistas a la argumentación de su realismo empírico supone por doquier el tiempo. Así se echa de ver, en efecto,

[22] "Todo lo que siempre aparece en el ser separado de espacio y tiempo es un fenómeno físico". (Scheler, M., Los ídolos del autoconocimiento, ed. cit., p. 56).

[23] En efecto, el tratamiento filosófico del espacio depende de la elucidación del tiempo -y no viceversa-, en virtud tanto de la prioridad metafísica del movimiento como de la peculiar posición gnoseológica -relativa al método- del tiempo. Más adelante me referiré a esta última.

THÉMATA. Revista de Filosofía, Nº50 julio-diciembre (2014) pp.: 151-175 doi: 10.12795/themata.2014.i50.07 
en la noción kantiana de fenómeno, entendido como configuración temporal esquemáticamente trazada sobre la forma a priori del sentido interno. Kant dota al concepto de configuración temporal de una significación en parte ilustrativa y sugerente, y en parte -a nuestro modo de ver- errada, de la que efectivamente se sigue un grave perjuicio para la metafísica.

No hay inconveniente en la consideración de la unidad del tiempo como orden formal que vincula las diferencias reales percibidas, según una perspectiva también sugerida por la Analítica trascendental. En tal sentido se ha afirmado aquí que la unidad temporal rige la exclusión de las diferencias reales recíprocamente excluidas. No porque el tiempo mismo constituya la ley o principio metafísico de aquella exclusión -lo es el movimiento-, sino porque como forma, el tiempo es índice del diverso vincularse recíproco las diferencias que se excluyen.

El tiempo es forma, como bien dice Kant, porque su propia diferencia establece el vínculo que -en estratos diversos- mantiene unidas a las determinaciones reales recíprocamente excluidas. Pero, por la misma razón, yerra Kant cuando convierte en opaco el índice mismo cuya función era manifestar el vincularse recíproco de las diferencias recíprocamente excluidas. En sentido inverso afirmamos aquí la condición articulante -es decir, formal- del tiempo. La multiforme estratificación de la unidad temporal significa por su parte que el tiempo no es sólo unidad de orden articulante (de las diferencias recíprocamente excluidas), sino también forma diversamente articulable. La diversa articulación de la unidad temporal es establecida en correlación con la diversidad de niveles en la intencionalidad cognoscitiva. Insisto: el hecho de que el tiempo articule de modos diversos significa que el tiempo no es sólo forma unitiva sino también forma configurable. El método trascendental en sentido rectificado expone la pluralidad de los estratos temporales en correlación con la esencia respectiva del acto cognoscitivo que en su caso objetiva el tiempo.

Esa doble condición del tiempo -forma articulante y articulable- resulta además solidaria con la condición de índice gnoseológico que atribuimos al tiempo. La forma articulante de las diferencias reales recíprocamente excluidas puede ser a su vez articulable si y sólo si: a) el tiempo es una forma manifestativa; $y b$ ) la realidad es susceptible de manifestación aspectual en diversos estratos ${ }^{24}$. Correlativamente: cabe que la realidad sea susceptible de manifestación multiforme -en estratos- si y sólo si la forma manifestativa es diversamente articulable; en efecto: en caso contrario los estratos quedarían desvinculados unos de otros de modo que no manifestarían la realidad.

Adviértase: el tiempo articula -excluye y une- las diferencias en cuanto que es su manifestación aspectual legítima -adecuada- y no única. Pero no

[24] La noción de estrato de realidad es propuesta por Max Scheler, en conexión con la forma del tiempo, especialmente en Los ídolos del autoconocimiento: cfr. ed. cit., p. 32.

THÉMATA. Revista de Filosofía, №50 julio-diciembre (2014) pp.: 151-175 doi: 10.12795/themata.2014.i50.07 
cabría integración cognoscitiva sin acoplamiento de estratos manifiestos, y no habría acoplamiento de estratos si la forma manifestativa en un nivel no fuera conocida en el nivel superior. Ese desplazamiento de la forma manifestativa desde un nivel intencional a otro exige diversas articulaciones en la propia forma, en correspondencia de identidad intencional con la esencia del acto manifestativo (en cada nivel). El principio aristotélico según el cual el cognoscente en acto es lo conocido en acto permite comprender que la forma manifestativa de un estrato real sea cabalmente proporcionada por el acto que opera el alumbramiento de lo real -según ese preciso estrato-.

La multiforme articulación del tiempo es por lo tanto solidaria con su condición de índice gnoseológico, manifestativo del articularse de las diferencias reales en diversos estratos intencionales. Ahora bien: puesto que la articulación de la forma temporal es diversa, podríamos plantearnos si cabe hablar de un máximo; es decir, si existe una forma articulativa del tiempo tal que no quepa otra articulación superior. La respuesta ha de ser afirmativa: llamaremos articulación plena del tiempo a aquella tal que no permita -más allá de sí misma- ulterior integración de la unidad temporal. Pues bien: la presencia mental es semejante articulación plena del tiempo. Esta es la razón de que la presencia mental -la articulación del tiempo en presencia- sea denominada por Polo límite. Por mi parte, empleo para la presencia mental la expresión articulación formal plena del tiempo. Es preciso introducir en este punto dos precisiones:

En primer lugar: la articulación temporal puede ser plena -excluir una forma articulativa superior- sólo si ella misma no es temporal (aunque sean temporales las diferencias que ella articula). No es así en cambio en el caso de las configuraciones parciales o sensibles del tiempo, es decir, en el de aquellas cuya integración según niveles resulta proseguible. En suma: la forma articulante del tiempo es a su vez articulable solo si ella misma es temporal. La razón es que sólo si la forma manifestativa es temporal la exclusión manifestativa de las diferencias temporales es susceptible de reducción en el orden manifestativo. Por el contrario, la articulación plena del tiempo es tal que su unidad es cierto ápice conforme al cual las diferencias que se manifiestan excluidas no admiten ulterior integración sin perjuicio del mismo carácter de la manifestación. En este sentido dice Aristóteles que las esencias son como los números y habla de aprehensión de los indivisibles. Las esencias, es decir, las manifestaciones de las formas según la articulación plena del tiempo, son núcleos diferenciales inconcusos, en el sentido aludido: su manifestación está concluida, es improseguible en la línea en que en cambio, hasta llegar hasta ellas, se acoplaron los estratos intencionales en función de la flexibilidad de la forma temporal.

La segunda precisión es la siguiente: la articulación plena o inteligible del tiempo no equivale, sino que excluye, la plena unicidad del tiempo. La unicidad plena del tiempo sería la plenitud de la presencia, la presencia colmada 
desde sí misma de Hegel, que excluiría de suyo -suprimiría- la legitimidad de las configuraciones temporales parciales ${ }^{25}$.

En conclusión: puesto que el tiempo es índice válido del vincularse de las diferencias recíprocamente excluidas según niveles diversos, el tiempo mismo es susceptible de configuración según grados diversos. A la configuración plena del tiempo -que no debe confundirse con su plena unicidad-llamamos presencia mental, o articulación plena inteligible del tiempo. La unicidad plena del tiempo sería en cambio la autopresencia, que por excluir de suyo la configurabilidad parcial del tiempo ha de rechazarse sin más. La articulación plena del tiempo vendría proporcionada, según se ha dicho, por la forma, no temporal ella misma, que introducida en el tiempo otorga a éste el ápice de su carácter de índice cognoscitivo: la transparencia ${ }^{26}$.

Con tales prenotandos, acerquémonos ahora a la noción de esquema trascendental. Kant la propone en orden a homogeneizar el concepto con la imagen ${ }^{27}$. La idea del esquema a priori parece sugerida por los conceptos de las figuras geométricas ${ }^{28}$, cuya misma objetividad es según Kant su legalidad constructiva $a$ priori con relación a la pluralidad espacial. El espacio isomorfo - difuso ${ }^{29}$ - queda definido a priori, pongamos por caso, si cierta ley esquemática de índole constructiva nos obliga a poner los puntos en equidistancia a otro que hace de centro. La ley es esquemática porque no impone, por ejemplo, la longitud que haya de tener la eventual figura construida; pero con todo es ley, porque repite la construcción de acuerdo con unos parámetros generales.

Análogamente, entiende Kant, cabe esta versión de los conceptos puros a modo de leyes aprióricas configurativas de la pluralidad temporal; y así dar cuenta del inextricable problema de la continuación entre entendimiento y sensibilidad, a la par que se esclarece el misterio de la anticipación en el

[25] Cfr. Hegel, W.G. F, Enzyklopäedie der philosophischen Wissenschaften im Grundisse, Heidelberg, 1817, $2^{\text {a }}$ edición, Berlín 1827; 3 a edición, ibíd. 1830; ed, cast. R, Valls, Enciclopedia de las ciencias filosóficas en compendio, Alianza Editorial, Madrid, 1997, §§ 257-259, pp. 315-319.

[26] Esta última consideración permite dar razón de las expresiones que empleo para aludir al contenido de realidad cuya posición excluyente rige la forma del tiempo. La equivalencia entre determinación y diferencia prefiere, no obstante, esta última en función de su especial connotación gnoseológica. El método filosófico no puede tener otro punto de partida: lo real en cuanto cognoscible es diferenciado -determinación, pero mejor, diferencia-, y hasta carece de sentido, en mi opinión, el establecimiento de una posición de realidad intrínsecamente indiferenciada. De ahí que haya de recusarse completamente la noción kantiana de cosa en sí, en la que con razón se encuentra un hierro de madera.

[27] Cfr. $K r V$ B 176 A 137.

[28] Cfr. $K r V$ B 180 A 14.

[29] Análogamente, a la pluralidad homogénea indefinida, elemental y carente de determinación inteligible de la forma kantiana del sentido interno puede denominarse tiempo difuso. Sobre semejante unidad difusa trazan las funciones categoriales sus esquemas, que serían las complexiones temporales definidas.

THÉMATA. Revista de Filosofía, №50 julio-diciembre (2014) pp.: 151-175 doi: 10.12795/themata.2014.i50.07 
conocimiento de las leyes naturales ${ }^{30}$. Con vistas a tal propósito, la pluralidad temporal isomorfa -idéntica con la pura forma de la intuición interna- ha de presentar algunos caracteres que la hagan susceptible de recibir configuraciones diversas. Es obvio que si la pluralidad temporal pura fuera de suyo completamente informe, no cabría disponer de distinto modo sus elementos. Adviértase de paso cómo juega la imaginación en la construcción de la teoría kantiana del tiempo. El tiempo resulta -valga el ejemplo- una especie de plastilina capaz de recibir distintas configuraciones. Pero no tendría esa disposición una plastilina tan amorfa que no presentara algunos caracteres diferenciados.

Los elementos temporales que permiten la combinatoria serían los instantes: momentos vacíos dispuestos en hilera, tales que admiten relleno o vaciado, y relleno continuo o discreto, etc. En la $K r V$ Kant enumera ciertos respectos del tiempo en conexión con los tipos de categorías. Se habla de serie, contenido, orden y conjunto ${ }^{31}$. Cada una de tales respectividades expone la configurabilidad del tiempo vista desde cada uno de los cuatro tipos de funciones unificantes -extraídas por su parte de la forma lógica del juicio-. En suma: la configurabilidad del tiempo sería su disposición plástica, con arreglo a la cual presenta sus elementos a diversas modalidades combinatorias. Las cuatro modalidades no serían exactamente combinaciones de elementos temporales sino más bien órdenes combinatorios posibles a que se presta la plasticidad de los elementos temporales. Así, por ejemplo, si se considera el tiempo desde la faceta de su contenido, puede estar lleno (realidad) o vacío (negación); si se considera el tiempo en su faceta sucesiva puede combinarse la permanencia (sustancia)-lleno en un tramo- o la sucesión (causa-efecto) -secuencia regular de llenos distintos-. (He prescindido en los dos ejemplos de la terna categorial restante).

Deseo resaltar en este punto el tratamiento kantiano de la conformación del tiempo de acuerdo con los esquemas de la sucesión -en las Analogías de la experiencia-, porque manifiesta de modo especial la suposición del tiempo por parte de Kant. La suposición del tiempo es, según se ha dicho, su consideración a modo de sustancia, de cosa que existe por sí misma, con independencia del contenido temporal. Kant no acepta que el tiempo sea cosa en sí -puesto que es forma de la intuición interna-, pero en apoyo de su realismo empírico, trata de hecho al tiempo de este modo. Por eso, en el marco de la consideración del esquema de la permanencia y la sucesión, la sustancia es identificada con el tiempo.

El razonamiento de Kant es el siguiente: a pesar de las distintas posibilidades combinatorias mencionadas, el tiempo conforma una serie unilateral, su conformación es enteramente rígida. Sólo caben tres modos del tiempo:

[30] Cfr. Vigo, A., "Determinación y reflexión", en Flamarique, L.- González, A.M. (eds. asoc.), Doscientos años después. Retornos y relecturas de Kant, Anuario Filosófico, XXXVII/3 (2004), pp. 777 y ss.

[31] Cfr. $K r V$ B 185 A 145.

THÉMATA. Revista de Filosofía, Nº50 julio-diciembre (2014) pp.: 151-175 doi: 10.12795/themata.2014.i50.07 
permanencia, simultaneidad y sucesión ${ }^{32}$. Ahora bien: no podemos percibir el tiempo en sí mismo, sino sólo lo que ocurre en el tiempo. Por lo tanto, juzgamos de la simultaneidad y la sucesión de las cosas porque tomamos el tiempo mismo como lo permanente ${ }^{33}$. Lo permanente en el plano del fenómeno es la pura sucesión con arreglo a la que se mide la relativa permanencia, la simultaneidad y la relativa sucesión de los fenómenos.

Lo que realmente permanece es el tiempo, la sucesión pura de los fenómenos en el tiempo, no del propio tiempo ${ }^{34}$. El tiempo mismo no se sucede sino que en él permanecen y cambian los fenómenos. Por lo tanto el tiempo es la sustancia de la realidad fenoménica: -adviértase: la materia, el hypokéimenon, de Aristóteles-. La sustancia es la representación intuitiva de la propia forma del tiempo, de modo que la categoría de sustancia no sólo se aplica válidamente al correspondiente fenómeno, sino que tal aplicación hace de condición de cualquier otra.

Así se comprende también el carácter funcional de los conceptos puros. La sustancia es de suyo incognoscible -es en todo caso el tiempo, que no puede percibirse por sí mismo-, pero sirve para estratificar de manera correlativa los fenómenos: el que eventualmente permanece hace de sustancia de los que sobre él se suceden ${ }^{35}$. Sobre esta base de la permanencia de la pura sucesión critica Kant después los paralogismos de la psicología racional. La categoría de sustancia no es aplicable al fenómeno interno porque ahí sólo hay -en el plano de la intuición- una pura sucesión ${ }^{36}$. Es distinto en lo que se refiere al fenómeno externo, porque entonces la intuición cuenta también con la relativa estabilidad fenoménica que proporciona la intuición del espacio ${ }^{37}$. Y así el esquema permite la estabilización de determinados fenómenos sobre el marco general de la sucesión de los otros ${ }^{38}$.

Me parece haber resaltado, con el desarrollo precedente, los puntos que más interesaban: primero, si el tiempo es susceptible de configuraciones diversas, queda sugerida la posibilidad de distintas formas de unidad temporal. Luego no sólo la secuencia. La secuencia es la unidad imaginativa del tiempo. Segundo: si la forma del tiempo es de hecho pensada en términos de unidad abarcante de lo real físico, ¿de dónde procede la convicción de que sólo el tiempo y ninguna otra cosa es lo permanente del mundo (en el plano del fenómeno)?

[32] Cfr. $K r V$ B 219 A 177.

[33] Cfr. $K r V$ B 225 A 182.

[34] Cfr. $K r V$ B 226 A 183.

[35] Cfr. $K r V$ A 400.

[36] Cfr. $K r V$ B 413; B 420.

[37] Cfr. $K r V$ A 381.

[38] Vid. la refutación de Scheler al planteamiento kantiano en la crítica de los paralogismos de la psicología racional en Ética, ed. cit., pp. 502 y ss.

THÉMATA. Revista de Filosofía, №50 julio-diciembre (2014) pp.: 151-175 doi: 10.12795/themata.2014.i50.07 
Tal es la tesis que en definitiva conduce a negar la realidad en sí de la realidad empírica, esto es, a sentar su idealidad trascendental. Sólo el tiempo mismo, la pura forma del sentido interno sustenta, subyace, todo lo demás constituye mero epifenómeno de semejante forma sustentante. Pero como se trata al cabo de una forma del sentido interno, nada real determinado subyace. Puede preguntarse, pues, a Kant qué es lo que en definitiva abarca la unidad abarcante o si sólo se abarca a sí misma.

Si el tiempo por sí mismo no es percibido, como muchas veces dice Kant, sino las cosas que en él permanecen y se suceden, ¿en virtud de qué se afirma que el tiempo mismo es la única permanencia fenoménica? Obviamente tan sólo en función del axioma previo introducido en la estética trascendental, de la que en realidad depende toda la $K r V$. Como el tiempo es la forma del sentido interno, ni se conoce realidad alguna, ni lo que se conoce fenoménicamente será más que esa forma de acuerdo con sus diversas configuraciones. El tiempo supuesto por todas partes, también en la primera antinomia de la dialéctica trascendental, donde tanto tesis como antítesis parten asimismo de la suposición del tiempo. En tal sentido no ocurre, como dice Kant, que una y otra parezcan probar confirmando la impotencia de la razón pura, sino más bien que ninguna parece hacerlo, porque ambas exhiben un supuesto bastante tosco ${ }^{39}$.

El equívoco que atribuye al tiempo imaginativo consistencia ontológica se sustenta sobre la conciencia intelectual de tiempo, no suficientemente depurada. Pero ha de existir una buena razón para que el tiempo imaginativo -la sucesión indefinida- resulte espontáneamente extrapolado en calidad de marco más extenso de la existencia del mundo y de las cosas. Este frecuente y casi inevitable equívoco de parte de la tendencia natural de nuestra fantasía, se sustenta por cierto en la noticia intelectual -no suficientemente depurada- de la articulación del tiempo entero. En ningún caso podría ser proporcionado por la propia imaginación.

De entrada, es verdad que la imaginación reproduce sus objetos de acuerdo con su disposición dentro del marco de la sucesión temporal ${ }^{40}$. Pero la propia imaginación no puede representar este esquema. Ahora bien. El

[39] La primera antinomia de Kant es refutada, desde la perspectiva dialéctica, brevemente en la $4^{\mathrm{a}}$ observación al cap. I de la secc. I del Libro Primero de La ciencia de la Lógica; y más extensamente en la observación $2^{\mathrm{a}}$ del cap II de la sección II del mismo Libro (Cfr. G.W.F. Hegel, Wissenschaft der Logik, Gesammelte Werke, Hrg. Der Rheinisch-Westfälischen Akademie der Wissenschaften, Felix Meiner, Hamburgo, 1968-; ed. cast. F. Duque, Ciencia de la lógica, I: La lógica objetiva, Universidad Autónoma de Madrid, Abada Editores, Madrid, 2011, pp. 335 y ss. Convengo con Hegel en estimar la tosquedad de los argumentos que Kant esgrime como supuestas pruebas de la antinomia. Ya Tomás de Aquino rebatía la pretendida prueba del origen temporal del mundo, y en cuanto a la antítesis de la primera antinomia, la suposición del tiempo vacío - con sus elementos indiscernibles- no puede resultar más endeble. Una y otra suponen la realidad del tiempo con independencia de las cosas temporales, en definitiva proceden de la mala sustancialización de la temporalidad antes mencionada.

[40] Vid. Fabro, C., Percepción y pensamiento, trad. J.F. Lisón, EUNSA, Pamplona, 1978.

THÉMATA. Revista de Filosofía, №50 julio-diciembre (2014) pp.: 151-175 doi: 10.12795/themata.2014.i50.07 
esquema imaginativo es susceptible de iluminación intelectual. La frecuente extrapolación del tiempo imaginativo como marco de consistencia de lo real es por lo tanto obra del entendimiento, digamos, poco ejercitado. Podríamos incluso decir que el ejercicio metafísico más pedestre comienza por aquí: extiende sin conversión el título de incontestable esfera ontológica al orden de la sucesión, previamente iluminado en el comienzo mismo de la vida intelectual.

En cambio, la articulación presencial del tiempo significa la forma de unidad temporal según la que el objeto se destaca con relación a la mera fenomenidad $^{41}$. Podemos tomar de Kant la idea del fenómeno como configuración temporal cuya sanción objetiva exige la inclusión en la unidad entera del tiem$\mathrm{po}^{42}$. Podemos tomarla, siempre que salvemos los extremos siguientes: $1^{\circ} \mathrm{La}$ propia condición fenoménica tiene un carácter, por llamarlo así, vehicular ${ }^{43}$. Eso significa que carece de sentido la consideración del fenómeno -y, por lo tanto, de la forma temporal- a modo de pantalla: la forma manifiesta de la exclusión de las diferencias reales sensibles, no puede ser al mismo tiempo la forma de la opacidad envolvente de tales diferencias. $2^{\circ}$ La unidad temporal del fenómeno es parcial, de modo que la objetividad sensible no llega a ser exenta. Llamamos esencia al objeto intelectual precisamente en función de que la unidad con él destacada es suficiente, y a este título correlativa respecto de la unidad entera del universo - esencia en sentido propio-. La unidad entera del universo es, según Polo, el implícito del abstracto, precisamente en cuanto que la abstracción es articulación del tiempo entero ${ }^{44}$. En suma: el objeto inteligible destaca esencia porque es obtenido en función de la articulación del tiempo entero. Esta unidad entera del tiempo no es real, sino el mismo carácter inteligible, la presencia mental. Pero sólo a través de ella cabe noción del tiempo abarcante. La exención objetiva es propiamente propiciada por la presencia mental, como el propio Kant entrevé con su exigencia de que el entendimiento sancione la objetividad del fenómeno. Sin embargo, como en Kant la intelección se limita a configurar desde fuera la forma del tiempo, la exención objetiva lograda se frustra y la unidad abarcante entrevista se limita a la de la experiencia posible.

[41] "El fenómeno no es el objeto de conocimiento, sino, más bien, es el conocimiento como fenómeno, como aparecer, esto es, como pura apariencia, como puro perspectivismo sensible (...) La razón de esto estriba en que el fenómeno es aquello conocido respecto de lo cual ninguna subjetividad se distingue: no hay precisamente sujeto aperceptivo del fenómeno" (Polo, L., La crítica kantiana del conocimiento, J.A. García González (ed.), Cuaderno de Anuario Filosófico, $\mathrm{n}^{\circ}$ 175, Servicio de Publicaciones de la Universidad de Navarra, Pamplona, 2005, p. 25).

[42] Repárese en que la unidad entera del tiempo no equivale a su plena unicidad, pues hemos recusado esta última como incompatible con la diversa configurabilidad de la forma temporal.

[43] Vid. el tratamiento de la noción de fenómeno en Scheler, M., Los ídolos del autoconocimiento, ed . cit., pp. 29 y ss.

[44] Cfr. Polo, L., Curso de teoría del conocimiento t. IV, EUNSA, Pamplona, 2004, pp. 558 y ss.

THÉMATA. Revista de Filosofía, №50 julio-diciembre (2014) pp.: 151-175

doi: 10.12795/themata.2014.i50.07 


\section{c) La unidad del tiempo como cifra de la realidad física}

¿De qué modo se opone la forma de lo temporal a la exhibición directa de la determinación real? Desperdigando la diferencia conocida según la multiplicidad de un reparto que no permite su concentración: agua es aquí y allí, agua es fría y caliente, agua es bebida, hielo y H2O, y ello según una secuencia rígida -el tiempo- que establece ocurrencias dispersas y aparentemente irreductibles de lo que, no obstante, no deja de ser lo mismo.

Lo mismo entendido que agua es simplemente agua, no agua fría o caliente o hielo -y ni siquiera $\mathrm{H} 2 \mathrm{O}-$, sino aquello mismo que todos entendemos cuando pensamos agua, y que tampoco precisa coincidir con la imagen que se viene a la mente de cada uno y que a este propósito resulta una representación imaginativa fortuita. Y sin embargo el famoso mono del experimento ${ }^{45}$-en contraste con la ciega y sordomuda Hellen Keller ${ }^{46}$ no fue capaz de reparar en que el agua que bebía era capaz de apagar el fuego: para el mono la doble ocurrencia espacio temporalmente dispersa del agua distanciaba las diferencias del agua percibida hasta constituirlas en cosas simplemente distintas.

¿De qué modo lo intelectualmente exhibido, no siendo la forma trasparente del tiempo (la presencia mental), es sin embargo lo temporal del tiempo? Ante todo: ¿qué es lo temporal del tiempo? Lo temporal del tiempo es el contenido de realidad que lo es en cuanto ocurre, dura y se distiende justo en aquella dispersión que -cara al conocimiento- interpone la forma del tiempo. El contenido real directamente exhibido -cancelada la dispersión que se interponeno ha de carecer por cierto de la referencia al tiempo, porque en tal caso, ¿se entendería agua o más bien, el dominio de lo directamente entendido habría de reducirse al espectro de los objetos matemáticos, intemporales y muertos?

Agua como contenido real ocurrente, duradero y disperso -aquello que todos entendemos cuando pensamos agua-incluye la referencia al tiempo como que es justo la acción de agua, el imponerse real, la vigencia múltiple y dispersa -y con todo concentrada- de cierto núcleo de realidad irreductible. Manifestamos que entendemos agua cuando decimos agua, como Hellen Keller cuando acierta con un mismo signo para referirse a aquello mismo que por fin se ha abierto paso en su mente. Pero lo que decimos con agua es la acción de agua, el ser vigente o extender su poder en el tiempo de aquel núcleo de realidad irreductible: tal es la acción de agua, ejercicio poderoso de acuosidad, por emplear esa relamida expresión.

La expresión de lo entendido de este modo es el verbo. El verbo incluye referencia al tiempo ${ }^{47}$, expresa la acción remansada y extendida: el remansarse

[45] Cfr. Pinillos, J.L., Principios de psicología, Alianza Editorial, 1987, p 442.

[46] Me refiero a la conocida historia narrada en la película El milagro de Ana Sullivan, de Arthur Penn, 1962.

[47] Cfr. Polo, L., Curso de teoría del conocimiento t. II, EUNSA, Pamplona, 1985, pp. 287 y ss.

THÉMATA. Revista de Filosofía, Nº50 julio-diciembre (2014) pp.: 151-175 doi: 10.12795/themata.2014.i50.07 
y extenderse de la acción, su configuración determinada -según su concentrarse en un núcleo irreductible-. Si el abstracto no diera noticia del tiempo carecería de referencia intencional, simplemente, de contenido. Si a la forma del abstracto - su estatuto formal, la presencia- denominamos articulación plena del tiempo, a su contenido, la determinación inteligible directa, la llamamos esencia inteligible. Ahora bien: la esencia inteligible no sólo es obtenida en presencia sino que, precisamente por serlo, su contenido intencional es referente al tiempo. El abstracto es cierta iluminación del fantasma concerniente a la forma articulante de las diferencias reales recíprocamente excluidas. En el nivel intencional de la imaginación esa forma es el tiempo sucesivo, cuya rigidez es precisamente depuesta en virtud de la mencionada iluminación intelectual.

Es frecuente cierta exposición de la conversio ad phantasmata que tiende a separar el estatuto del objeto de la primera operación intelectual, a distanciar la objetividad abstracta con relación a la imagen que constituye su condición sensible. De este modo, se entiende la conversio a modo de un regreso, una vuelta destinada a vencer la distancia previamente interpuesta. Polo ha insistido en lo inadecuado de este planteamiento hasta el punto de rehusar la denominación de concepto para el objeto de la primera operación intelectual, al que denomina precisamente abstracto. En la gnoseología poliana ${ }^{48}$, la interposición de un estrato de objetividad separado o deslindado de la inmediata continuidad intencional con las imágenes sensibles, corresponde en cambio al concepto (no al abstracto). De ahí que, en el planteamiento de Polo, el concepto introduzca el plano intencional propiamente representativo con el que se da entrada a la lógica racional. Tal es la razón de que Polo designe el concepto como primera fase de la operación racional, de acuerdo con la que la mente opera la devolución a la realidad de lo pensado. El concepto es primera fase operativa de la razón porque en él la mencionada devolución no queda enteramente cumplida, esto es, queda detenida en un cierto espacio por así decir intermedio entre la primera objetividad abstracta y la realidad explícitamente afirmada en el juicio. Ese hiato explica también la precipitación con que se atribuye valor ontológico a caracteres que en verdad pertenecen sólo a la peculiar objetividad conceptual. La extrapolación ontológica de tales caracteres es denominada por Polo metafísica prematura.

El método gnoseológico ha de ajustar su propio comienzo al de la vida intelectual, pero esta última se incoa como abstracción de la esencia inteligible a partir del fantasma. A la forma articulativa del tiempo en virtud de la cual el saber se anticipa obteniendo esencia inteligible hemos llamado articulación del tiempo entero. Aquí comienza también el método, porque la articulación del tiempo entero proporciona un comienzo suficientemente vasto. No así la objetividad sensible, cuya articulación temporal propia debe decirse disminuida o

[48] Ibid.

THÉMATA. Revista de Filosofía, Nº50 julio-diciembre (2014) pp.: 151-175 doi: 10.12795/themata.2014.i50.07 
parcial. Es preciso acercarse cuidadosamente a esta última noción, es decir, sin perder de vista que la articulación temporal sensible queda esclarecida por la inteligible y no viceversa.

Examínese el enunciado que formulábamos anteriormente: las diferencias reales sólo existen y son conocidas según en el modo de su mutua exclusión. En la matización de este enunciado se juega la suerte de la doctrina del método, considerada desde la perspectiva de la forma temporal, puesto que ésta última puede considerarse índice de la elucidación metafísica.

La noción de forma o articulación temporal adquiere en efecto un valor metódico. La unidad del tiempo - que es su forma- tiene que ver con el método de la filosofía primera. La dificultad está en reparar en que el valor gnoseológico de la articulación del tiempo es bipolar: mientras en directo da cuenta del estatuto del conocimiento objetivo, de manera indirecta cifra el límite objetivo. En este último sentido la articulación del tiempo entero es raíz positiva de la problematicidad del saber. El adelantamiento del saber -según la articulación presencial del tiempo- es positivamente problemático. De ahí que la metafísica exija reducción metódica del tiempo. Así se matiza también la aparente equivalencia que introduce el enunciado aludido: las diferencias reales sólo existen y son conocidas según el orden de la mutua exclusión; pero más propiamente: el orden manifestativo de la exclusión recíproca de las diferencias reales es pórtico para el acceso al orden real de su coexistencia excluyente.

Dicho de otro modo: puesto que el ordo et conexio idearum no equivale sin más al ordo et conexio rerum, resulta preferible subrayar en la noción de forma temporal la significación connotativa del orden metódico -que hace de pórtico-, mientras que se reserva para el movimiento el significado alusivo al orden temático o propiamente metafísico. Así, la forma temporal sería el orden de las diferencias reales excluyentes con arreglo al que se accede al vincularse real entre las diferencias recíprocamente excluyentes. Este vínculo real es el movimiento. El tiempo no sólo es la medida del movimiento sino también su índice, y para el método principalmente esto último.

\section{Conclusión: la contraposición de las nociones de esencia y fenómeno en función del tiempo}

La misma denominación forma temporal responde al propósito de sugerir la flexibilidad que requiere el tratamiento gnoseológico de la unidad del tiempo. La unidad del tiempo, su articulación formal, es en efecto plena o parcial, y la articulación parcial se distribuye en niveles intencionales diversos. De otra parte, la articulación del tiempo se llama formal en cuanto se distingue del contenido real del tiempo al que cabe denominar vigencia del ser temporal.

Por articulación parcial del tiempo debe entenderse la noticia temporal esencialmente relativa, esto es, en función, no sólo del movimiento interno del 
viviente $^{49}$, sino también del disponerse respectivo de los movimientos externos vitalmente significativos. La percepción sensible del tiempo es esencialmente relativa sin que ello vaya en perjuicio de la objetividad del tiempo percibido. El tiempo sensible es objetivo porque los movimientos que sustentan su noticia son reales -y objetivamente conocidos-. Aunque, de otra parte, está claro que no ha de atribuirse a la objetividad del tiempo las mismas características que a las diferencias que con él se perciben y en él se comparan. El hecho de que las posibles comparaciones entre los movimientos significativos para el organismo sean, por así decir, infinitas, este hecho, digo, no quita objetividad al valor de tales comparaciones. Pero sí excluye taxativamente la posibilidad de que el tiempo sensible alcance la plenitud de la articulación.

Ni siquiera la articulación del tiempo entero es susceptible de comparecencia objetiva. La articulación del tiempo entero es la condición propia del objeto, su estatuto, y, por lo tanto, su límite. La comparecencia objetiva en sentido propio se reserva a la inteligencia, cuya operación instaura precisamente ese estatuto al que llamamos articulación del tiempo entero. Cualquier noticia del tiempo sensible informa, pues, de una articulación parcial del tiempo, según la cual pasa a contenido intencional cierta forma articulativa de las diferencias reales que en niveles sensibles inferiores permanece tácita. Pero en cualquier caso la noticia temporal compareciente no abarca -deja fuera-; establece una medida relativa, cierta respectividad entre movimientos cuyo contorno global deja impreciso.

En cualquier percepción acontece una vivencia del tiempo sensible, como también en las experiencias de placer, de dolor, de deseo. En la impaciencia del deseo se experimenta como un extenderse interno del tiempo. Se ofrece de este modo una noticia comparativa entre los movimientos correspondientes al propio organismo -sediento, pongamos por caso-y el objeto -el agua, allí lejos- que satisfaría el deseo. De igual modo son también expresamente convocadas las intenciones de pasado por parte de la memoria, o de futuro por parte de la cogitativa. La memoria reproduce lo acaecido bajo la expresa indicación del vínculo entre la experiencia presente y la serie vivida que se remonta a lo rememorado. Pero en ninguno de estos casos, lo sensiblemente notado es aquel tiempo $u n o^{50}$ que se extiende más allá de los contornos imprecisos de la propia experiencia y al que se refiere frecuentemente Husser ${ }^{51}$ en sus descripciones de la actitud natural de la conciencia. Hay ciertamente noción de este tiempo uno, pero de ninguna manera se tratará de una noticia sensiblemente

[49] Cfr. Scheler, M., Ética, ed. cit., pp. 568-569, n. 62.

[50] Cfr. Heidegger, M., Prolegómenos para una Historia del concepto de tiempo, trad. J. Aspiunza, Alianza Editorial, Madrid, 2006, p. 21.

[51] Cfr. Husserl, E., -Ideen zu einer reinen Phänomenologie und einer phänomenologischen Philosophie I, Husserliana III, M. Nijhoff, La Haya, 1950; Ideas relativas a una fenomenología pura y una filosofía fenomenológica, I, trad. J. Gaos, FCE, Madrid, 1993, \& 27, pp. 64 y ss.

THÉMATA. Revista de Filosofía, №50 julio-diciembre (2014) pp.: 151-175

doi: 10.12795/themata.2014.i50.07 
experimentada. Lo sensiblemente experimentado del tiempo es indefectiblemente un cierto acotamiento, una respectividad incompatible con el abarcar irrestricto del tiempo uno.

Tal es la razón que a mi parecer sustenta la conclusión kantiana sobre la imposibilidad de establecer un fenómeno correspondiente a la idea trascendental de mundo. El error de Kant está a mi juicio en restringir el alcance cognoscitivo - por parte de la conciencia que abarca el tiempo- a la esfera del fenómeno. Kant razona: puesto que el mundo como tal no es enteramente dado en el orden del fenómeno, lo dado del mundo es mero fenómeno. La esfera intelectualmente abarcable es según Kant la experiencia posible, aprióricamente abarcable por la conciencia trascendental. La confusión está en exigir la integridad fenoménica del tiempo como condición de realidad de lo dado en el tiempo; o en otra dirección: en restringir el dominio de la conciencia intelectual del tiempo a la esfera de la experiencia posible. La integridad fenoménica del tiempo no cabe de suyo, porque la articulación sensible del tiempo es parcial; y la conciencia intelectual del tiempo no se coextiende con el orden de lo posible sino que precisamente acompaña al señalamiento de la esfera de lo real físico.

En efecto. La abstracción suele explicarse en atención exclusiva al contenido determinado -el abstracto- obtenido. Aquí hemos propuesto atender más bien a la forma de la unidad según la que se dispone ese contenido. Las diferencias sensibles configuran en plexos cuyas más simples disposiciones parecen ser el espacio y el tiempo. A mi modo de ver, puede prescindirse del espacio, en razón de que su naturaleza no es esencialmente distinta de la del tiempo, sino esta misma considerada en su detención y contracción. Tanto el espacio como el tiempo son objetos formales, y tanto el uno como el otro dan noticia del modo de ser de diferencias cuyo existir exige recíproca exclusión. Pero el espacio contrae la más vasta disposición de aquellas diferencias en el tiempo, deteniéndolas - de acuerdo con su representación objetiva- en un punto; un punto, que es como corte transversal del tiempo.

¿Es por lo tanto el tiempo la sustancia general del mundo, el flujo que alimenta todas las cosas y del que el espacio mismo se nutre, como su misma posición detenida? De ninguna manera, sino el mero índice del ser físico real según el movimiento. Índice significa a este propósito cifra, no imposición formal receptiva según la estructura del sentido humano, sino más bien estrato de la realidad, configuración objetiva adecuada en la que comparece lo real ante las facultades de conocimiento humano. La metafísica depura y aquilata la vigencia de ese comparecer en dirección a los primeros principios. En este sentido procede recoger la sugerencia que proporciona la noticia del tiempo uno, marco más extenso de la existencia de las cosas para ulteriormente depurar su significado.

La unidad del tiempo es pues la cifra de su articulación inteligible plena, en contraposición con la cual se establece el alcance significativo de la 
expresión articulación parcial o sensible del tiempo. En atención a otras nociones invocadas en la discusión precedente con Kant, puede añadirse aquí lo siguiente: fenómeno se asimila a articulación parcial del tiempo; la articulación plena o del tiempo entero se corresponde con la esencia. Dábamos antes la razón a Kant en que no cabe fenómeno del mundo, a partir de la imposibilidad de principio de comparecencia objetiva sensible de la unidad abarcante, de la que en cambio es cifra la noticia intelectual del tiempo entero. La textura del fenómeno, por llamarla así, es por cierto, como dice Kant, la de cierta disposición configurativa del tiempo: multiplicidad de diferencias de acuerdo con un orden cuya forma articulativa es el tiempo. Kant considera que la objetividad del fenómeno ha de venir asegurada por la asistencia de la conciencia trascendental que incluye la representación en la unidad más amplia del tiempo uno, para él equivalente al ámbito de la representación posible para una conciencia en general. La unidad del tiempo kantiano es inteligible, no sensible; es el abarcar de la pluralidad por parte del yo pienso como condición de cualquier representación significativa. La unidad del tiempo es en Kant inteligible -la condición misma de inteligibilidad-pero no es esencia, hasta el punto de que su propia realidad no puede ser establecida en función de la carencia de fenómeno correspondiente; o más propiamente: en función de que la noción misma de fenómeno excluye en Kant la posibilidad de acceso hasta la esencia, por razón de establecerse la barrera del tiempo como obstáculo insalvable para la declaración de realidad en sí de lo conocido. En suma: la función lógica queda divorciada en Kant de la función cognoscitiva.

Aún sin que se acepte el planteamiento general, ya se ha dicho que hay aquí sugerencias sumamente aprovechables. En primer lugar, hay acierto en vincular la condición de lo inteligible con la unidad del tiempo -aunque sea en un sentido disminuido que requiere corrección-. Pero, en segundo lugar, también hay acierto en advertir que el fenómeno como textura temporal exige integración en la más amplia que proporciona la unidad global del tiempo. La exigencia de integración avala la objetividad fenoménica misma. Por aquí nos topamos igualmente con la descripción de Husserl sobre la actitud natural de la conciencia, en que el tiempo uno hace de contorno impreciso que avala por así decir el rigor, la firmeza de todo aquello auténticamente dado en la experiencia.

Husserl ${ }^{52}$ toma tal continuidad o legalidad constante del tiempo uno como referente que permite precisamente poner entre paréntesis lo dado en la experiencia: el contenido intencional incluye índices referenciales que podrían entrar en contradicción con el decurso ulterior de la experiencia, esto es, no incluirse dentro del marco general de legalidad que avala a la experiencia en su conjunto. Por este camino practica Husserl su epojé y opera la clausura del fenómeno en su propia consistencia ante la conciencia trascendental; es decir, lo convierte en esencia.

[52] Ibid.

THÉMATA. Revista de Filosofía, Nº50 julio-diciembre (2014) pp.: 151-175 doi: 10.12795/themata.2014.i50.07 
Recusamos aquí ambos extremos: ni el fenómeno es esencia, como quiere Husserl, ni impide el acceso a ella, como dice Kant, sino que se describe como articulación parcial del tiempo. Para que el fenómeno fuera esencia habría de contar con una textura temporal propia, que es precisamente la que en la doctrina de Husserl le asigna el tiempo inmanente de la conciencia. El tiempo inmanente de la conciencia establece la consistencia esencial del fenómeno y en tal sentido lo dota de una configuración temporal plena, y sin embargo -según Husserl- no intelectual, sino más bien preconsciente y sensible. A mi modo de ver esta posición es inaceptable y metódicamente inviable: entre otras cosas, todo el esclarecimiento fenomenológico depende de una intromisión de la mirada intelectual en aquel oscuro reino - de la preconsciencia-, intromisión que luego no parece reconocida por los propios fenomenólogos.

Pero la sugerencia sigue siendo aprovechable. Tanto uno como otro autor establecen la legalidad de la experiencia en su conjunto, en correspondencia con la unidad de la configuración temporal como marco que fija el estatuto de la objetividad. Y a partir de aquí podemos glosar más detalladamente la diferencia entre las configuraciones temporales que hemos llamado respectivamente plena y parcial. De hecho, el propio sentido interno está dotado de la capacidad de discernimiento de la representación, que por incluirse dentro del marco general de la experiencia, es -concurrente el ejercicio intelectual-tomada como real. El sentido interno discierne su intención del tiempo pasado en cuanto efectivamente vincula la experiencia presente con las anteriores y determina con precisión el marco real de la experiencia correspondiente con el tiempo uno. Los sueños o las ensoñaciones también presentan configuraciones temporales, pero en este caso la articulación temporal parcial carece de vínculo con la noticia con que se cifra la articulación temporal plena.

De acuerdo con esta última se establece la consistencia inteligible de lo real que aquí hacemos equivaler a la esencia. Se ha dicho que la esencia en su consistencia inteligible es por derecho propio discreta, es decir, núcleo de determinación inteligible no confuso: en este sentido no hay una única esencia sino muchas. Pero la consistencia inteligible asiste a cada núcleo esencial con el mismo derecho que asiste a todos según una misma consistencia, que es la que proporciona la articulación del tiempo entero.

Hegel pretende la reducción intelectual de la secuencia imaginativa, exponiéndola como repulsión del uno vacío de contenido. El pensamiento negativo daría cuenta así del hilvanarse de la sucesión indefinida de instantes. La pluralidad de estos últimos se contrae de este modo a la reiterada posición de este uno repelente. Pero un ajuste como el que Hegel propone exige contar con este uno que se repele no resbale a la suposición de un contenido. Eso no es posible.

La negación -el pensamiento negativo- no llega a sustituir el comienzo, es decir, no alcanza a reponer la determinación de su contenido. En cambio la forma de la articulación temporal entera asegura el contenido -no entero- 
dentro de un horizonte suficientemente vasto. La negación tiene su cometido propio. La tesis de Polo es que la negación es advertencia prosecutiva de la insuficiencia del comienzo. De ahí que aunque la insuficiencia del comienzo no sea susceptible de saldo negativo, la negación indique de suyo la positividad del saber. Este es el uso que de ella hace Aristóteles, con su sanción heurística de la no contradicción. El saber es positivo, porque su puro adelantamiento problemático es imposible.

Aunque la negación no reduzca sola la insuficiencia del comienzo, indica la necesidad de ajuste de la forma negativa del saber. Decimos aquí en efecto que esa forma negativa con que el método se detiene es susceptible de esclarecimiento retrospectivo. El ajuste saldaría cuentas con la insuficiencia del adelantamiento; y desde la perspectiva del método, enderezaría también el planteamiento prepotente y ostentoso que desemboca en aporía de principio.

El ajuste del método salda la insuficiencia del primer comienzo, considerada en el orden mismo del método. Considerada en este orden, digo, porque en el suyo propio la insuficiencia del primer comienzo no es negativa. La insuficiencia en cuestión es negativa exclusivamente en el plano en que, por decirlo así, no pretende serlo; o bien -como está claro en Hegel- cuando se propone que la pura indigencia sea la condición precisa que anima al método. La iluminación retrospectiva de las aporías de principio esclarecería la impertinencia semejante modo de plantear el comienzo de la filosofía. 
